\title{
PENERAPAN METODE FAST TERHADAP PENGEMBANGAN SIM-RS UNTUK PENINGKATAN PELAYANAN DI RUMAH SAKIT
}

\section{The Implementation Fast Method For Management Information System Hospital Development For Improving Service Hospital}

\author{
Putri Nur Rahma ${ }^{1}$, Makhrajani Madjid ${ }^{1}$, Herlina $^{1 *}$, Ayu Dwi Putri Rusman ${ }^{1 * *}$, \\ Noer Bahry Noer ${ }^{2}$, Fridawati Rivai ${ }^{2}$ \\ ${ }^{1}$ Fakultas Ilmu Kesehatan Universitas Muhammadiyah Parepare \\ ${ }^{2}$ Fakultas Kesehatan Masyarakat Universitas Hasanuddin Makassar \\ *muinherlina@yahoo.com \\ **ayudwiputri88@yahoo.co.id
}

\begin{abstract}
ABSTRAK
Penerapan SIM telah diamanatkan oleh Undang-undang untuk segera diterapkan yakni pada UU Nomor 44 Tahun 2009 Pasal 52. Penelitian ini bertujuan untuk Mengetahui kendala yang menjadi factor penghambat dalam penerapan system informasi manajemen di rumah sakit. Menghasilkan strategi paling efektif yang dapat mengoptimalkan penerapan system informasi manajemen di rumah sakit. Menggunakan metode FAST dalam merancang system informasi managemen rumah sakit dirumah sakit. Metode yang digunakan kualitatif dan kuantitatif. Metode kualitatif pada penelitian ini digunakan untuk membantu proses identifikasi, dalam metodologi pengembangan sistem informasi manajemen rumah sakit dalam guna mendukung keputusan manajemen pelayanan. Metode kuantitatif digunakan untuk mengevaluasi kualitas informasi sebelum dan sesudah pengembangan sistem informasi.Hasil penelitian menunjukkan kendala utama belum diterapkannya system informasi manajemen di rumah sakit adalah mahalnya biaya membangun system informasi manajemen, Strategi yang efektif untuk menerapkan system informasi manajemen di rumah sakit adalah perkuat komitmen manajemen rumah sakit bahwa sistem informasi manajemen akan berjalan, Dengan metode FAST dapat memperbaiki kualitas informasi melalui aplikasi system informasi manajemen di rumah sakit. Sistem informasi yang dikembangkan perlu diaplikasikan secara on-line dengan menggunakan Local Area Network untuk penggunaan multiuser.
\end{abstract}

Kata Kunci: Kendala, strategi, metode FAST

\section{ABSTRACT}

The aims of research are to find out the obstacle that to be inhibition factors in the implementation of Management Information System Hospital, then it produces the most effective strategy that can optimize the implementation of management information system. Next, it uses FAST method for designing Management Information System Hospital). The method used qualitative and quantitative. Qualitative method of the research is used to help the identification process in methodology of development hospital for management information system in order to support service management decision. Quantitative methods are used to evaluate the pre quality of information and post of the development information systems. The result of research indicates that the main obstacle has not applied for Management Information System is the expensive cost of build Management Information System Hospital. The most effective strategy is for the implementation Management Information System Hospital is the hospital management has to commit that management information will run well. By the FAST method, it can repair the information quality through Management Information System Hospital application in Hospital. The information system of development needs to apply online way of Local Area Network by using multiuse. 


\section{PENDAHULUAN}

Keputusan menteri kesehatan Republik Indonesia No 1410/Menkes/SK/X/ 2003 tentang penetapan penggunaan sistem informasi rumah sakit di Indonesia, diharapkan mampu mengukur mutu penyelenggaraa pelayanan kesehatan sesuai standar yang berlaku dan etika profesi. Bila dilihat hubungan antara informasi untuk perencanaan dan informasi untuk pengendalian dan pengambilan keputusan yang berbentuk strategis, taktis dan teknis ternyata secara keseluruhan memerlukan informasi. ${ }^{1}$

Penerapan sistem informasi manajemen (SIM) di rumah sakit meliputi pelayanan medik, pelayanan keperawatan, administrasi dan pelayanan penunjang semua kegiatan akan menghasilkan data rumah sakit. Data tersebut dikumpulkan, dikelolah, disajikan, dianalisis dan penyampaian data dalam bentuk informasi terhadap manajemen rumah sakit.

Aditama menyatakan bahwa SIM amat berperan dalam akuntansi manajemen dan audit medik. Akuntansi manajemen meliputi penagihan pembayaran pasien,pembayaran dan insentif sesuai beban kerja, pemesanan logistik rumah sakit, pengurusan dengan pihak ketiga dalam asuransi dan perencanaan keuangan.Penerapan SIM juga telah diamanatkan oleh Undang-undang untuk segera diterapkan yakni pada UU Nomor 44 Tahun 2009 Pasal 52 Ayat 1 bahwa "Setiap Rumah Sakit wajib melakukan pencatatan dan pelaporan tentang semua kegiatan penyelenggaraan Rumah Sakit dalam bentuk Sistem Informasi Manajemen Rumah Sakit".

Sistem informasi rumah sakit adalah suatu tatanan yang berurusan dengan pengumpulan data, penyajian informasi yang dibutuhkan untuk kegiatan rumah sakit. Unsur sistem informasi rumah sakit yaitu a) tugas: menyiapkan informasi untuk kepentingan pelayanan rumah sakit, b) tujuan: sistem informasi rumah sakit, dan subsistemnya antara lain: subsistem pengembangan dan operasional subsistem c) komponen: ada input, proses, output dan balikan kontrol.

Tuntutan pelayanan informasi untuk pasien di suatu Rumah Sakit semakin meningkat, pelayanan ini harus didukung dengan sistem informasi yang dapat memberikan kemudahan dalam pelayanan kesehatan bagi masyarakat serta lembaga rumah sakit tersebut.Penerapan Sistem Informasi Manajemen Rumah Sakit merupakan sistem komputerisasi yang mengintegrasi antar unit di rumah sakit. SIM-RS akan membantu mencegah kebocoran data karena data akan tersimpan dengan aman, pengimputan data klaim untuk pihak ketiga lebih cepat, dan tidak akan ada lagi pungutan liar diluar biaya pelayanan yang diberikan kepada pasien karena SIM-RS dirancang menganut kebijakan data terpusat sehingga manipulasi tarif tidak mungkin terjadi lagi. ${ }^{3}$ 
Kegiatan pelayanan yang diselenggarakan di rumah sakit antara lain berupa pelayanan unit rawat jalan, rawat inap, pelayanan penunjang medis dan pelayanan farmasi. Kian hari peningkatan jumlah pasien baik dari dalam maupun luar kota semakin banyak. Setiap rumah sakit sebenarnya telah mencanangkan penerapan SIM-RS ini dalam rangka peningkatan pelayanan kepada masyarakat dan kebijakan ini juga merupakan bagian dari penerapan standar mutu sebuah Rumah Sakit. Namun, hingga Tahun 2016 ini kebijakan penerapan SIM-RS di rumah sakit belum dapat berjalan sebagaimana yang telah direncanakan sebelumnya. ${ }^{4}$

Walaupun perusahaan-perusahaan pengembangan SIM-RS telah banyak berdatangan untuk melakukan kerjasama dengan pihak rumah sakit dan pihak rumah sakit telah membentuk susunan panitia namun sampai saat ini penerapan SIM-RS belum dapat tercapai. Hal ini dikarenakan pemerintah selaku stakeholders yang juga mendukung terwujudnya SIM-RS di rumah sakit belum menemukan titik temu dengan pihak rumah sakit sehingga sampai saat ini banyak rumah sakit belum dapat menerapkan SIM-RS. ${ }^{4}$

Tujuan penelitian ini adalah Mengetahui kendala yang menjadi faktor penghambat dalam penerapan SIM-RS di rumah sakit. Menghasilkan strategi paling efektif yang dapat mengoptimalkan penerapan SIM-RS di rumah sakit. Menggunakan metode
FAST untuk merancang SIM-RS di rumah sakit

\section{METODE PENELITIAN}

Jenis penelitian ini adalah penelitian kualitatif dan kuantitatif. Metode kualitatif pada penelitian ini digunakan untuk membantu proses identifikasi, dalam metodologi pengembangan sistem informasi rawat inap pelayanan penyakit dalam guna mendukung keputusan manajemen pelayanan. Metode kuantitatif digunakan untuk mengevaluasi kualitas informasi sebelum dan sesudah pengembangan sistem informasi, dengan demikian bentuk desain penelitian menggunakan pre experimental (one group pre and post test design) yaitu dilakukan pengamatan sebelum pengembangan selanjutnya dilakukan perlakukan lalu dibandingkan kualitas informasi sebelum dan sesudah perlakuan. Perbedaan kedua hasil pengukuran dianggap sebagai efek perlakuan.

Waktu dan pelaksanaan Penelitian ini dilaksanakan di rumah sakit pada tahun 2018. Sampel dalam penelitian ini yang ditetapkan adalah pihak manajemen rumah sakit, dan sampel ruangan pengembangan system informasi manajemen rumah sakit. Data yang diperlukan dalam penelitian ini adalah data primer yang diperlukan dalam penelitian ini meliputi: kendala prioritas penghambat penerapan Sistem Informasi Manajemen Rumah Sakit dan strategi yang paling efektif yang dapat mengoptimalkan Sistem Informasi 
Manajemen Rumah Sakit di rumah sakit yang diperoleh pengumpulan data yang dilakukan langsung pada sumber pertama melalui pengamatan (observasi) dan wawancara.

Instrument yang di gunakan dalam penelitian ini adalah kuesioner dan panduan wawancara mendalam tentang kendala dan strategi yang efektif dalam penerapan system informasi manajemen rumah sakit, alat tulis menulis, Hanphone atau telpon seluler yang mempunyai fasilitas merekam suara

Data yang diperoleh dari hasil wawancara diolah secara manual dengan mengelompokkan hasil wawancara sesuai tujuan penelitian. Selanjutnya disajikan secara kualitatif dalam satu matriks dan dalam bentuk analisis isi (content analisis) yang disertai penjelasan sesuai dengan pedoman atau standar yang ada. Analisis analitik dilakukan untuk menguji kualitas informasi sebelum pengembangan sistem informasi dan sesudah dilakukan pengembangan sistem informasi dengan menggunakan Uji Tanda (Sign Test). Uji tanda biasanya digunakan untuk mengetahui pengaruh sesuatu. Uji tanda didasarkan atas tanda-tanda positif atau negatif dari perbedaan antar pasangan pengamatan bukan atas besarnya perbedaan.

\section{HASIL DAN PEMBAHASAN}

Sistem informasi manajemen saat ini merupakan sumber daya utama, yang mempunyai nilai strategis dan mempunyai peranan sangat penting sebagai daya saing serta kompotensi utama sebuah organisasi dalam menyongsong era informasi ini. Dibidang kesehatan terutama rumah sakit sangat membutuhkan keberadaan sistem informasi manajemen rumah sakit untuk meningkatkan kualitas pelayanan bagi masyarakat.

Faktor pendorong pengembangan sistem informasi pelayanan penyakit dalam yaitu memperbaiki sistem informasi yang lama, dimana sistem yang lama ditemukan permasalahan, adanya peluang untuk pengembangan sistem informasi dan yang paling penting anjuran langsung dari direktur rumah sakit (directive). Metodologi yang digunakan untuk pengembangan sistem adalah dengan metodologi FAST, hasil penelitian berdasarkan FAST sebagai berikut :

Analisis masalah bertujuan untuk mempelajari dan menganalisis sistem yang sedang digunakan, mengidentifikasi dan mencari solusi serta membatasi ruang lingkup pengembangan sistem informasi. Pada saat studi pendahuluan diketahui adanya permasalahan, peluang dan permintaan dari pengguna sistem untuk memperbaiki dan mengembangkan sistem informasi yang sedang digunakan. Adapun masalah, peluang dan arahan sebagai berikut : Berdasarkan wawancara yang dilakukan dengan pihak manajemen rumah sakit, berikut kutipan wawancara dengan sekertaris direktur rumah sakit 
"Sebenarnya dulu SIM RS pernah ada cuma untuk saat ini tidak berjalan karena kami memutuskan kerja sama dengan pihak ketiga penyedia program SIM RS. (AJ, 01-07-2017)

“Dan untuk saat ini kami belum tahu dengan siapa kami bekerjasama dan apakah perusahaan itu bisa mengikuti kemauan kami disini dan yang paling utama adalah dana. (NA, 01-07-2017

Dari hasil wawancara diatas maka dapat diketahui bahwa SIM RS disana belum berjalan meskipun pihak manajemen sangat mengerti pentingnya pengadaan sistem informasi manajemen. Kendala ini cukup signifikan karena tanpa adanya dana mustahil untuk menerapkan SIM RS di rumah sakit.

Mahalnya biaya membangun SIM RS karena peralatan yang dipakai dalam pengadaan SIM cukup mahal dimana setiap unit di rumah sakit harus memiliki perangkat komputer tetapi hal ini dapat teratasi apabila penganggaran untuk SIM dapat terlaksana. Rumah sakit tak lagi perlu memusingkan tentang tingginya biaya yang harus dikeluarkan untuk penerapan SIM karena telah dianggarkan setiap tahunnya dan tidak mengganggu pendapatan rumah sakit.

"teknologi canggih yang mendukung penerapan SIM RS memiliki nilai yang cukup tinggi mulai dari pengadaan komputer disemua unit dimana ini memakan banyak dana juga pengadaan software SIM RS "'(DV, SM, 07-07-2017)
“ sebenarnya disini juga para pegawai belum seтиa menguasai sistem informasi dan tidak semua data tersimpan dikomputer belum lagi mindset pegawai kami kurang ....(ML, DV, 07-07-2017)

"sebenarnya kami disini sangat mengerti pentingnya SIM di rumah sakit karena dapat mengurangi kebocoran data tapi karena terkendala di biaya yang mahal...(SU, TH, 07-07-2017).

Persepsi mahalnya biaya membangun SIM RS tergantung dari person, karena manfaat yang dihasilkan akan jauh lebih banyak dari biaya yang dikeluarkan dan juga sangat menguntungkan rumah sakit. Kurangnya pegawai rumah sakit yang menguasai sistem informasi terlihat dari kurangnya pegawainya yang mengetahui tentang SIM yang

Agar penerapan SIM RS dapat berjalan lancar dan sesuai dengan apa yang diharapkan oleh pihak manajemen rumah sakit dan para pegawai, maka perlu adanya strategi jitu agar semuanya itu dapat terwujud

Berikut kutipan wawancara dengan pihak manajemen rumah sakit:

"......Selama ini belum ada laporan yang kami terima dari pelayanan medis atau keperawatan dari rawat inap penyakit dalam, semonga model informasi yang anda usulkan bisa cepat direalisasikan agar kami bisa menentukan kebijakan selanjutnya mengenai mutu pelayanan...." 
“.....Selama ini belum ada laporan yang diterima, menurut kami meskipun tidak kami minta laporanya, setidaknya sekali sebulan kami dapat informasi tentang pelaksanaan asuhan keperawatan... kami sangat mendukung saran saudara supaya ada sistem informasi yang bisa menyelesaikan permasalahan ini......"

"Manajemen rumah sakit pernah memberikan pelatihan tentang SIM tapi cuma sekali karena kurangnya dana makanya baru sekali diberikan (SM, TH, 21-07-2017)

"kalau dari pihak manajemen rumah sakit kami tetap berkomitmen SIM akan berjalan di rumah sakit ini karena sudah kami wacanakan dari dulu (AJ, DR, 24-07-2017) "kami sudah menganggarkan pengadaan SIM tapi belum menjadi prioritas utama kami karena biayanya yang mahal...(ML, SU, 24-07-2017)

Strategi dalam pengembangan SIM menjadi sangat penting mengingat banyak pegawai rumah sakit yang belum memahami jelas tentang sistem informasi manajemen dan mereka tidak mungkin mendukung penerapannya di rumah sakit, karena itu diperlukan perkenalan tentang SIM kepada seluruh komponen rumah sakit melalui pendidikan dan pelatihan

Sebelum menerapkan SIM RS diperlukan ketetapan komitmen oleh manajemen rumah sakit dan dapat melibatkan elemen-elemen rumah sakit agar tidak setengah-setengah dalam penerapannya sehingga membuahkan hasil yang diinginkan.komitmen yang tidak kuat membuat penerapan SIM ini dapat berjalan ditempat.

Metode FAST (Framework for the Application of System Thinking) untuk merancang sistem informasi manajemen di rumah sakit dapat dilihat pada tabel di bawah ini, Permasalahan dari sistem informasi pelayanan penyakit dalam di rumah sakit antaralain:

Tabel 1. Identifikasi Permasalahan Sistem Informas di rumah sakit Sebelum di kembangkan SIFO

\begin{tabular}{|c|c|c|c|}
\hline $\begin{array}{c}\text { Jenis } \\
\text { Analisis }\end{array}$ & Masalah & Penyebab Masalah & Solusi \\
\hline $\begin{array}{l}\text { Perform- } \\
\text { Ance }\end{array}$ & $\begin{array}{l}\text { a. Informasi yang dihasilkan belum } \\
\text { tersedia secara lengkap, informasi yang } \\
\text { disampaikan tidak tepat waktu } \\
\text { b. Waktu yang dibutuhkan kepala ruangan } \\
\text { untuk mengolah data pelayanan penyakit } \\
\text { dalam 3-4 hari }\end{array}$ & $\begin{array}{l}\text { Sistem informasi } \\
\text { manual, data pelayanan } \\
\text { semakin konpleks }\end{array}$ & $\begin{array}{l}\text { Pengembangan sistem } \\
\text { informasi berbasis } \\
\text { computer. }\end{array}$ \\
\hline
\end{tabular}




\begin{tabular}{|c|c|c|c|}
\hline \multirow[t]{29}{*}{ Informasi } & a. Output & Data yang diinput di & Mengembangkan \\
\hline & Informasi yang dihasilkan tidak & formulir pasien tidak & sistem informasi \\
\hline & lengkap, informasi yang dihasilkan & semua di proses & menghasilkan \\
\hline & antara lain: informasi BOR, informasi & menjadi informasi & informasi setiapsaat, \\
\hline & jumlah penyakit, informasi 10 besar & & lengkap dan dapat \\
\hline & penyakit & & diperoleh setiap saat \\
\hline & b. Input & & dengan bantuan \\
\hline & Tidak semua data yang ada di formulir & & software dan harware \\
\hline & pasien bisa diinput didalam buku & Form di buku registrasi & \\
\hline & registrasi data yang diinput antara lain & tidak lengkap & Memperbaiki/ \\
\hline & : data identitas pasien masuk dan & & menambah form \\
\hline & keluar, (non rekam meis, nama, umur, & & pendataan data \\
\hline & jeniskelamin, suku, cara keluar, cara & & \\
\hline & pembayaran jenis kunjungan), data & & \\
\hline & penyakit (diagnosa utama), data medis & & \\
\hline & (dokter yang merawat), data perawatan & & \\
\hline & (ruang rawat, kelas perawatan) & & \\
\hline & c. Proses: pengolahan data dengan cara & & \\
\hline & merekap data yang ada dalam buku & & \\
\hline & register dihitung satu demi satudengan & & \\
\hline & bantuan kalkulator membutuhkan & Belum menggunakan & \\
\hline & waktu selama 3-4 hari. & sistem informasi & Proses pengolahan data \\
\hline & d. Data tersimpan: & dengan bantuan & dengan bantuan \\
\hline & Belum menggunakan DBMS sehingga & softwerd dan harware & softwer dan hardare \\
\hline & sulit untuk di akses. Data tidak aman & & \\
\hline & dari kecelakaan an tidak dapat & & \\
\hline & \multirow[t]{3}{*}{ diorganisasikan. } & Penyimpanan data & \\
\hline & & belum menggunakan & Menyimpan data \\
\hline & & database & menggunakan database \\
\hline Ekonomi & $\begin{array}{l}\text { Keberadaan pasien sulit untuk ilacak, sulit } \\
\text { untuk melacak data pelayanan kepaa } \\
\text { pasien }\end{array}$ & $\begin{array}{l}\text { a. Pengolahan data } \\
\text { masih manual }\end{array}$ & $\begin{array}{l}\text { Dengan sistem bantuan } \\
\text { komputerkegiatan } \\
\text { pelayanan penyakit } \\
\text { dalam lebih transparan, } \\
\text { data pasien lebih } \\
\text { mudah dilacak }\end{array}$ \\
\hline $\begin{array}{l}\text { Keamana- } \\
\mathrm{n}\end{array}$ & $\begin{array}{l}\text { Sulit mengontrol data pasien, sulit } \\
\text { mengetahui error pemrosesan data yang } \\
\text { dikelolaolehkepala ruangan, belum ada }\end{array}$ & $\begin{array}{l}\text { Keamanan data dan } \\
\text { control trlalu lemah. } \\
\text { Data dikelolah di }\end{array}$ & $\begin{array}{l}\text { Dengan sistem } \\
\text { komputer data bisa } \\
\text { diback-up, digandakan }\end{array}$ \\
\hline
\end{tabular}




\begin{tabular}{|c|c|c|c|}
\hline & $\begin{array}{l}\text { croschek data antara medical record } \\
\text { dengan pelayanan penyakit dalam }\end{array}$ & $\begin{array}{l}\text { rumah dengan bantuan } \\
\text { kalkulator }\end{array}$ & dilakukan croscek \\
\hline Efisiensi & $\begin{array}{l}\text { Kegiatan input, prosespengolahan data } \\
\text { dilakukan oleh staf perawat yang } \\
\text { membutuhkan waktu } \pm 15 \text { menit/formulir } \\
\text { pasien sehingga mengurangi kontak } \\
\text { dengan pasien }\end{array}$ & $\begin{array}{l}\text { Semua kegiatan } \\
\text { administrasi } \\
\text { pelayananpenyakit } \\
\text { dalam dilakukan oleh } \\
\text { perawat dngan cara } \\
\text { manual }\end{array}$ & $\begin{array}{l}\text { Dengan sistem } \\
\text { komputer dapat } \\
\text { dicegah redundansi } \\
\text { data, informasi tersedia } \\
\text { realtime }\end{array}$ \\
\hline Service & $\begin{array}{l}\text { Informasi yang dihasilkan sistem lama } \\
\text { tidak akurat, sulit untuk di akss. }\end{array}$ & $\begin{array}{l}\text { Kesalahan alam proses } \\
\text { tabulasi dan entri data, } \\
\text { dikelolahdi rumah oleh } \\
\text { kepala ruangan }\end{array}$ & $\begin{array}{l}\text { Dengan sistem } \\
\text { informasi berbasis } \\
\text { komputer } \\
\text { informasiyang } \\
\text { dihasilkan lebih akurat } \\
\text { dan mudah diakses }\end{array}$ \\
\hline
\end{tabular}

Analisis keputusan untuk pemilihan solusi pengembangan sistem informasi berdasarkan fasilitas yang tersedia pada rumah sakit dengan pertimbangan kelayakan teknis, operasional, ekonomi dan jadwal yaitu;

Pemilihan sistem operasi pengembangan sistem informasi manajemen rumah sakit, berdasarkan hasil diskusi sistem operasi untuk pengembangan sistem informasi yang diusulkan pada penelitian ini yaitu Microsoft (MS) Windows dengan pertimbangan aplikasi ini telah tersedia, sumber daya manusia rumah sakit telah familer menggunakan Ms Windows. Pengembangan sistem informasi pelayanan rencana akan di on-line dengan server rumah sakit dengan menggunakan Local Area Network.

Pemilihan software (Tools) untuk kebutuhan sistem informasi yang diusulkan peneliti mengusulkan menggunakan program bahasa PHP dan MySQL dengan pertimbangan PHP merupakan software yang open source (gratis) dan dapat digunakan dengan sistem operasi lainya, PHP dapat diaplikasikan di Windows. Untuk mengelolah database peneliti mengunakan MySQL (multiuser database) yang menggunakan bahasa Structured Query Language dengan pertimbangan MySQL mampu menagani data yang cukup besar, penggunaan yang lebih familier (user-friendly), open source (gratis), mampu berinteraksi dengan programprogram aplikasi PHP dan program lainya

Perancangan sistem informasi manajemen rumah sakit guna mendukung keputusan manajemen pelayanan. Tujuan kegiatan ini adalah untuk perancangan database, input, output dan (interface) antar muka. Perancangan sistem menggunakan alat bantu antara lain DFD, kamus data, diagram 
konteks, daftar kejadian dan spesifikasi proses. Tahap perancangan sistem informasi penyakit dalam, sebagai berikut:

Rancangan Model sistem Tahap Pengembangan DFD dengan diagram konteks. DFD merupakan model logika dasar menggambarkan dari mana asal data dan kemana tujuan data, mengambarkan penyimpanan data dan proses transformasi data. Pada penelitian ini peneliti menggunakan simbol DFD yang dipakai menggambarakan data beserta proses transformasi yang dikembangkan oleh Yuoardon/De Marco.

Uji coba dilakukan dengan menginput data yang ada di buku registrasi pelayanan penyakit dalam, formulir pasien (mencakup kegiatan pelayanan medis dan keperawatan) data yang diinput yaitu data pada bulan Mei sebanyak 58 data transaksi pelayanan penyakit dalam dan Juni 11 data. Pendataan data pelayanan penyakit dalam dimulai dari tanggal 10 februari sampai 15 April 2018 dilakukan oleh perawat penyakit dalam dibantu dengan bimbingan peneliti. Setelah dilakukan ujicoba sistem informasi pelayanan penyakit dalam, peneliti menanyakan kembali kepada user mengenai kualitas informasi yang dihasilkan sistem baru.

Evaluasi kualitas informasi mengukur kualitas informasi sebelum dan sesudah dikembangkan sistem informasi, pengukuran dilakukan dengan menggunakan kuesioner.
Data pelayanan penyakit dalam semakin kompleks dan belum menggunakan database manajemen sistem (DBMS), mulai dari Pendataan, pengolahan dan penyajian informasi dilakukan secara manual yang membutuhkan waktu (Pendataan membutuhkan waktu \pm 15 menit/pasien dan mengelolah data pelayanan penyakit dalam menjadi informasi bulanan 3-4 hari), harapan user dengan mengunakan sistem informasi berbasis komputer data akan terkelolah dengan baik, informasi yang dihasilkan guna mendukung keputusan manajemen pelayanan akan tersedia, lengkap, tepat waktu serta akurat dan mudah diakses. "...harapan saya setelah

dikembangkan sistem informasi berbasis komputer data pasien terkelolah dengan baik, dan informasi selalu tersedia setiap saat......." NH

“....jika sudah ada sistem yang mampu mengelolah data kegiatan pelayanan, dan hasilnya bisa diperoleh setiap saat akan lebih efektif lagi...." tidak perlu menunggu lama untuk pengambilan keputusan...."HM

Berdasarkan hasil wawancara dan observasi pada saat studi pendahuluan kepada pengguna sistem sangat setuju jika dilakukan perbaikan atau pengembangan dari sistem informasi yang lama kesistem informasi berbasis komputer. Dengan harapan data akan terkelolah dan informasi yang dihasilkan tersedia, tepat waktu guna membantu 
menentukan keputusan manajemen pelayanan dan strategi rumah sakit kedepan.

Manfaat-manfaat yang lain yang dapat di peroleh oleh rumah sakit dalam menerapkan SIM ini, antara lain : memberikan nilai tambah dengan meningkatkan efisiensi kerja, kecepatan penyelesaian pekerjaan administrasi, akurasi data, berpengaruh pada budaya kerja dengan integrasi data disetiap unit, peningkatan pelayanan, kecepatan mengambil keputusan, akurasi dan kecepatan identifikasi masalah, kemudahan penyusunan strategi, transparansi, koordinasi antar unit. ${ }^{5}$

Agar pada penerapan SIM dapat berjalan lancar dan sesuai dengan apa yang diharapkan oleh pihak manajemen Rumah Sakit dan para pegawai,maka perlu adanya strategi-strategi jitu agar semuanya itu dapat terwujud sebagai berikut, Manajemen diharapkan dapat memberikan pemahaman mengenai pentingnya Sistem informasi manajemen rumah sakit kepada setiap unsur dalam rumah sakit. Agar SIM berjalan sesuai dengan apa yang diharapkan maka perlunya pemahaman dari semua elemen rumah sakit. Hal ini dapat dilakukan oleh pimpinan atau direktur rumah sakit. ${ }^{6}$

Sebelum menerapkan Sistem Informasi Manajemen (SIM) ini, diperlukan ketetapan komitmen oleh manajemen Rumah Sakit dan dapat melibatkan elemen-elemen Rumah Sakit agar tidak setengah-setengah dalam penerapannya sehingga membuahkan hasil yang diinginkan. Komitmen yang tidak kuat membuat penerapan SIM ini dapat berjalan di tempat.

Memberikan pelatihan yang intensif kepada pengguna Sistem Informasi Manajemen (SIM) dimana dalam hal ini yaitu para staf dan pegawai Rumah Sakit yang diberikan pelatihan-pelatihan mengenai komputer ataupun pelatihan tentang sistem informasi yang berkaitan dengan Sistem Informasi Manajemen (SIM). Agar para staf Rumah Sakit dapat menjalankan sistem dengan baik dan benar sehingga tercapai kepuasan pelanggan yang diinginkan .

Memberikan fasilitas informasi yang memadai sehingga para unsur rumah sakit dapat denganmudah menerapkan SIM. Fasilitas informasi yang dimaksud disini yakni fasilitas yang dapat mendukung terlaksananya SIM itu sendiri. Pemberian insentif kepada setiap pegawai yang dapat memanfaatkan Sistem Informasi Manajemen (SIM) dengan lebih optimal. Pemberian insentif bagi pegawai Rumah Sakit yang mampu menjalankan SIM akan memberikan semangat baginya.

\section{KESIMPULAN DAN SARAN}

Kendala utama belum diterapkannya SIM RS di rumah sakit adalah mahalnya biaya membangun SIM RS. Strategi yang efektif untuk menerapkan SIM RS di rumah sakit adalah perkuat komitmen manajemen rumah sakit bahwa sistem informasi manajemen akan berjalan. Dengan metode FAST dapat memperbaiki kualitas informasi melalui aplikasi SIM RS di rumah sakit. Sistem 
informasi yang dikembangkan di rawat inap pelayanan penyakit dalam perlu diinstal dan dipakai secara single user atau dikembangkan dengan sistem on-line untuk pemakaian multiuser dengan menggunakan LAN, untuk memudahkan manajemen mengakses informasi pelayanan secara realtime. Pengadaan petugas administrator untuk mengelola data kegiatan pelayanan rawat inap.

\section{DAFTAR PUSTAKA}

1. Abas. 2009 Pengembangan Sistem Informasi Kesehatan Untuk Pelayanan Di Rumah Sakit Umum Daerah. Abasnr.blogspot.com. (2 April 2015)

2. Aditama Y C. Manajemen Administrasi Rumah Sakit. Jakarta : Universitas Indonesia (UI Press); 2011.

3. Anton Wijaya. 2010. Faktor Penghambat Penerapan SIMRS Di Rumah Sakit. Medianers.blogspot.com. ( 9 April 2015)

4. Kusharjanti F. 2013, Sistem Informasi Manajemen Rumah Sakit (SIM RS). Fiastri-k.blogspot.com (12 April 2015)

5. Widajat, R., Being Great And Sustainanble Hospital. Jakarta: PT Gramedia Pustaka Utama. 2009(5).

6. Herlin Nureni W. 2014. Sistem Informasi Manajemen Rumah Sakit.
7. Aprilia. 2010. Komponen Sistem Informasi. http.apr11-si.comuf.com (12 April 2015)

8. Azam M. Sistem informasi admisi pasien rawat inap untuk membantu pengambilan keputusan klinis dan administrasi di badan RSUD dr. $\mathrm{H}$ Soewondo Kabupaten Kendal. Semarang: Universitas Diponegoro; 2007.

9. Dharmawan Y., Sistem informasi efisiensi penggunaan tempat tidur unit rawat inap dengan menggunakan indikator grafik barber Jhonson di Rumah Sakit Panti Wilasa Citarum Semarang. Universitas Diponegoro: Semarang, 2006.

10. Departemen Kesehatan Republik Indonesia PerMenKes No 1410/MenKes/SK/x/2003 Tentang Penerapan Penggunaan Sistem Informasi Rumah Sakit di Indonesia. 2003.

11. Departemen Kesehatan Republik Indonesia. 2009, UU No 44 Tahun 2009 Tentang Sistem Informasi Manajemen Rumah Sakit

12. Efendi Rusman. 2011, Klasifikasi Rumah Sakit.

Fendhyuhamka.wordpress.com. ( 28 Maret2015). 